\title{
Artery of Percheron ischaemic stroke revealed by brain MRI DWI/ADC sequences
}

\author{
Jacopo C. DiFrancesco
}

Department of Neurology and Laboratory of Neurobiology, University of Milano-Bicocca, Monza, Italy

\section{Correspondence to} Dr Jacopo C. DiFrancesco, jacopo.difrancesco@gmail.com

Accepted 22 November 2017

\section{DESCRIPTION}

A 71-year-old Caucasian female patient presented with acute onset of visual disturbance, gait difficulties and fluctuation of consciousness.

Her medical history included artery hypertension, previous cardiac valve replacement with mechanical prosthesis, in treatment with oral anticoagulant.

An emergency CT scan resulted negative for acute lesions, haematological exams were normal, international normalised ratio (INR) was $>2.5$. The EKG revealed high-frequency atrial fibrillation, not previously known.

At the neurological examination, the patient presented drowsiness, easily resolved by verbal stimulus, bilateral divergent diplopia, with eye movements possible only horizontally and severe postural instability with retropulsion.

On the day after the onset of neurological symptoms, the patient underwent brain MRI without gadolinium. Axial fluid attenuation inversion recovery (FLAIR) sequences revealed diffuse cerebral vasculopathy in the bilateral white matter without evidence of acute lesions (figure 1). Diffusion-weighted imaging (DWI) sequences revealed the presence of recent ischaemic lesions in the territory of the artery of Percheron (AOP), involving the bilateral ventral thalamus portion and paramedian midbrain, confirmed by apparent diffusion coefficient (ADC) sequences (figure 2). The diagnosis of acute ischaemic stroke of the AOP of cardioembolic origin was made and oral anticoagulant therapy was

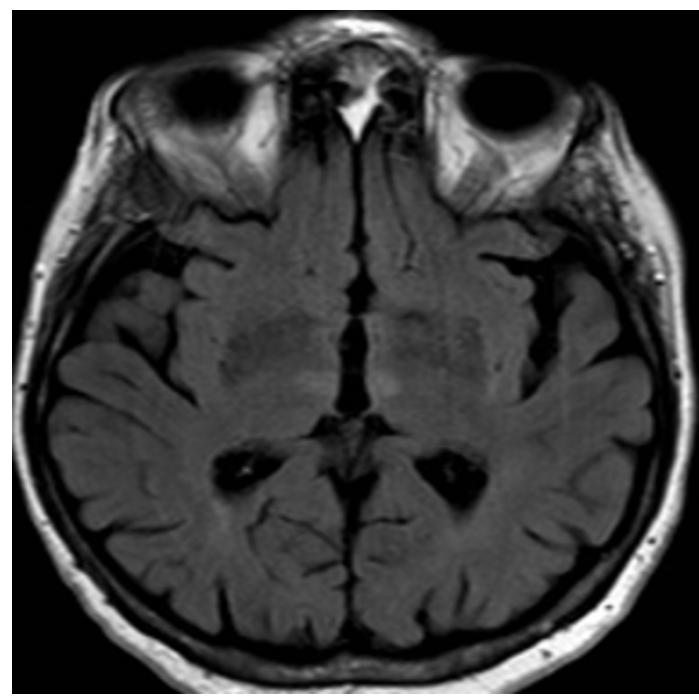

Figure 1 Axial brain MRI fluid attenuation inversion recovery (FLAIR) sequence of the bilateral thalamic infarct area, without evidence of acute lesions.
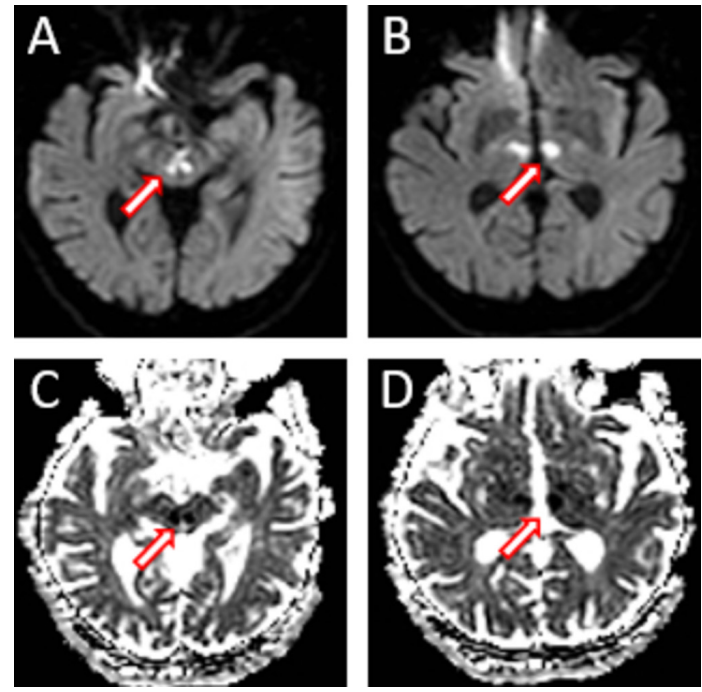

Figure 2 Recent ischaemic lesions in the bilateral ventral thalamus portion and paramedian midbrain revealed by diffusion-weighted imaging (DWI) $(A, B$; arrows) and apparent diffusion coefficient (ADC) (C, D; arrows) brain MRI sequences.

strengthened, with INR ranging from 3.0 to 3.5. Treatment with beta blocker bisoprolol $2.5 \mathrm{mg}$ daily was started with reduction of heart rate frequency. During hospitalisation, her clinical conditions progressively ameliorated, with complete recovery of fluctuation of consciousness. On discharge, vertical visual deficit was still present, but partially reduced and deambulation was possible only with support.

The AOP is a possible rare anatomic variant of the posterior cerebral circulation. This is a perforating artery deriving from the posterior cerebral artery, which divides into two branches to ensure the arterial circulation of the paramedian bilateral portion of the thalamus and the rostral midbrain. ${ }^{1}$

The acute occlusion of the AOP is a rare event, ${ }^{12}$ which can result from arterial embolism, atherothrombosis or cardioembolism. ${ }^{3}$ It is characterised by a typical triad of symptoms with altered mental state (mainly drowsiness, coma and hypersomnolence), vertical gaze palsy and memory deterioration. Other phenotypic manifestations can include speech disorders (generally dysarthria or aphasia), hemiparesis of variable severity, movement asymmetry or cerebellar ataxia and defects of ocular motility. $^{23}$

The peculiar clinical characteristics of the AOP infarction allow suspecting it precociously. However, other major clinical conditions as 
meningoencephalitis, epilepsy and metabolic or toxic processes must be excluded before in the process of differential diagnosis, with consequent delay in the identification and rapid treatment of the responsible cause.

Here we show that ordinary brain MRI T2/FLAIR sequences could fail to properly detect brain small lesions determined by the AOP occlusion. In this case, only the application of the DWI/ADC sequences allowed the identification of the

\section{Learning points}

Artery of Percheron (AOP) ischaemic stroke has peculiar clinical characteristics that allow to suspect it. However, other clinical conditions must be excluded before reaching the correct diagnosis.

- Ordinary brain MRI sequences (T1/T2) may fail to detect small ischaemic lesions, better identified by the application of diffusion-weighted imaging (DWI)/apparent diffusion coefficient (ADC) sequences.

- Brain MRI DWI/ADC sequences should always be included in the clinical suspicions of AOP ischaemic stroke. ischaemic lesions, leading to the correct diagnosis and consequent treatment.

This case report supports the importance of including brain MRI DWI/ADC sequences in the suspicions of AOP ischaemic stroke, in order to facilitate an earlier diagnosis and the proper treatment.

Contributors JCD dealt with conception and design of the work, acquisition, analysis or interpretation of data.

Competing interests None declared.

Patient consent Obtained.

Provenance and peer review Not commissioned; externally peer reviewed.

(C) BMJ Publishing Group Ltd (unless otherwise stated in the text of the article) 2017. All rights reserved. No commercial use is permitted unless otherwise expressly granted.

\section{REFERENCES}

1 Sandvig A, Lundberg S, Neuwirth J. Artery of percheron infarction: a case report. J Med Case Rep 2017;11:221.

2 Arauz A, Patiño-Rodríguez HM, Vargas-González JC, et al. Clinical spectrum of artery of Percheron infarct: clinical-radiological correlations. J Stroke Cerebrovasc Dis 2014;23:1083-8.

3 Hammersley D, Arora A, Dissanayake M, et al. Fluctuating drowsiness following cardiac catheterisation: artery of Percheron ischaemic stroke causing bilateral thalamic infarcts. BMJ Case Rep 2017;bcr2016218035.

Copyright 2017 BMJ Publishing Group. All rights reserved. For permission to reuse any of this content visit

http://group.bmj.com/group/rights-licensing/permissions.

BMJ Case Report Fellows may re-use this article for personal use and teaching without any further permission.

Become a Fellow of BMJ Case Reports today and you can:

- Submit as many cases as you like

- Enjoy fast sympathetic peer review and rapid publication of accepted articles

- Access all the published articles

- Re-use any of the published material for personal use and teaching without further permission

For information on Institutional Fellowships contact consortiasales@bmjgroup.com

Visit casereports.bmj.com for more articles like this and to become a Fellow 